\title{
Prenatal Diagnosis of Benign Extreme Hyperlordosis
}

Frederic Chantraine, MD, Boris Tutschek, PhD, Thibault Senterre, MD,

Malek Tebache, MD, Philippe Beauduin, MD, Jean-Pierre Schaaps, PhD

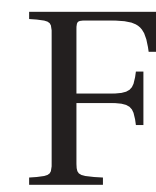

etal malposition due to persistent hyperextension of the lumbar spine (hyperlordosis) has only very rarely been reported. ${ }^{1}$ A literature research (key words: hyperlordosis, hyperextension, lumbar spine, opisthotonus, and prenatal) revealed only 1 published case with prenatal diagnosis. ${ }^{2}$ We describe a case detected by routine prenatal screening, review the literature, and discuss possible etiologies of congenital hyperlordosis.

Abbreviations

$\mathrm{MRI}$, magnetic resonance imaging

\section{Case Report}

A healthy 19-year-old primigravida with an unremarkable medical history had not received regular prenatal care. During her pregnancy, she had visited the emergency department twice, at 8 weeks for vaginal bleeding and at 24 weeks for a urinary infection. On both occasions basic sonographic examinations had shown normal fetal biometric measurements and heart rates; no abnormality had been noted. When she appeared again at 34 completed weeks to plan the delivery, 2-dimensional and volume sonography (V6-2 volume transducer, iU22 ultrasound system, and QLAB analysis software for volume data; Philips Healthcare, Bothell, WA) showed the fetal spine in extreme hyperlordosis: The lumbar spine was flexed dorsocranially by $180^{\circ}$ (3-dimensional skeletal rendering in Figure 1). Tomographic imaging from a static 3-dimensional volume confirmed the abnormal position on parallel sections of the fetal body; the stomach and bladder were visible on opposite sides of the spine (Figure 2). All other organs systems appeared normal. To corroborate these findings and to seek possible associated anomalies, magnetic resonance imaging (MRI) of the fetus was done (Philips 1.5-T unit), confirming the isolated hyperlordosis of the lumbosacral spine (Figure 3). Genetic amniocentesis revealed a normal karyotype $(46, \mathrm{XY})$. 


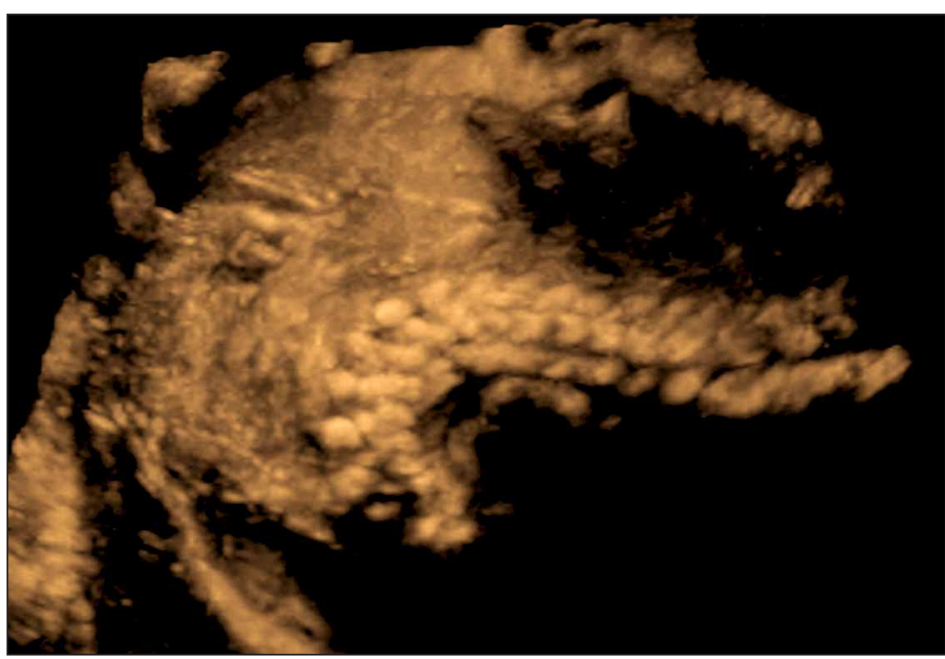

Figure 1. Three-dimensional rendering of the fetal spine (lateral aspect) showing hyderlordosis at 34 completed weeks.

Because of this positional anomaly and breech presentation, an elective cesarean delivery was performed at 39 completed weeks. A male neonate was delivered with a weight of $2750 \mathrm{~g}$, Apgar scores of 9 and 10 at 1 and 5 minutes, respectively, and a normal cord blood $\mathrm{pH}$. Immediately after birth, the apparently isolated hyperlordosis of the spine was confirmed; otherwise, the neonate appeared and behaved normally (Figure 4). Within the first 3 hours postpartum, the neonate spontaneously assumed a normal

Figure 2. Tomographic imaging of a sonographic volume in fetal hyperlordosis. The fetal stomach (panel 5, arrow 1) and bladder (panel 9, arrow 2) are on opposite sides of the spine.

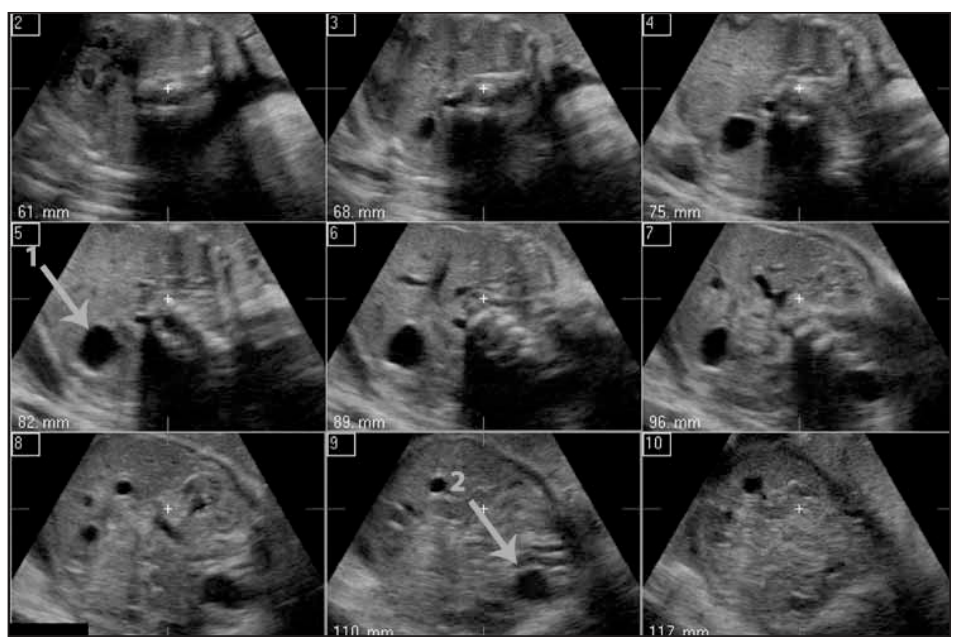

posture and could lie flat on his back. Sonographic and radiologic examinations after birth showed a normal abdominal situs and a spine with normal vertebral bodies. The neonate was discharged on day 4 of life. At pediatric follow-up at 5 months of age, the spine and posture were clinically normal and the overall development unremarkable (Figure 5).

\section{Discussion}

The etiologies of extreme congenital hyperlordosis are unknown. Maternal factors, known risk factors for fetal malpresentation, include high parity, pelvic tumors, uterine anomalies, anomalies of the pelvic bones, and prenatal pelvic/abdominal trauma. ${ }^{1,3}$ In our case, the patient's history and the detailed inspection of the uterus at cesarean delivery were completely unremarkable.

Possible fetal causes include the following: (1) a contracted lumbodorsal fascia, as reported by Ezaki and Herring ${ }^{1}$ in a case of hyperlordosis persistent after birth, requiring surgical release at 3 years of age; (2) "stiff man syndrome," as described by Klein et $\mathrm{al}^{4}$ in 3 cases of neonatal hypertonia in 1 family, transmitted in an autosomal dominant way and characterized by a generalized muscular hypertonus; (3) neonatal spasticity/opisthotonus secondary to cerebral lesions, eg, in intraventricular hemorrhage ${ }^{5}$; (4) metabolic neurodegenerative disease, the diag-

Figure 3. Fetal MRI (sagittal T2-weighted slice) showing a view of the complete fetus with extreme hyperlordosis of the spine. The spinal cord and midsagittal brain structures appear normal. Note how one fetal foot touches the occiput.

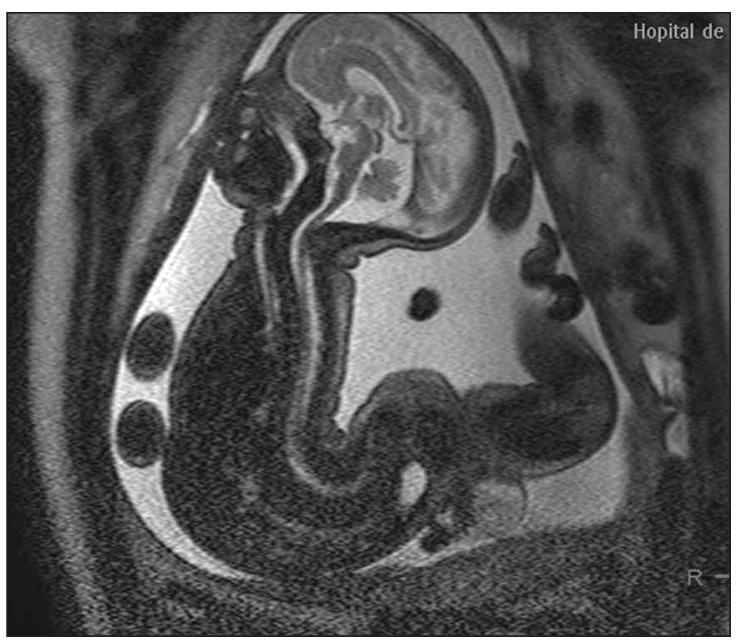




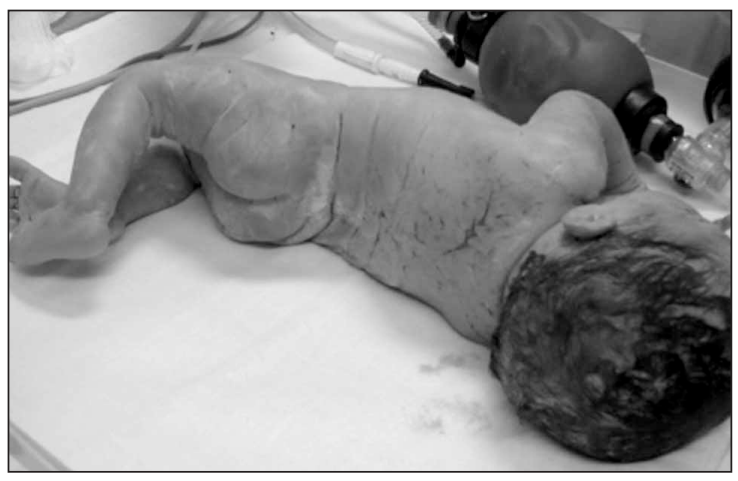

Figure 4. Congenital hyperlordosis in spontaneous regression immediately after birth.

nosis of which to our knowledge has never been made prenatally ${ }^{5}$; and (5) structural spinal anomalies such as hemivertebrae. ${ }^{6}$

Although reports on fetal hyperlordosis are very rare, several reports and case series exist about hyperextension of the fetal head. ${ }^{7-9}$ Similar to hyperlordosis, it may be isolated, especially in a breech presentation, in which it has a good prognosis, but it carries a poorer outlook when associated with other anomalies.?

Figure 5. Normal posture and development of the child at 5 months of age.

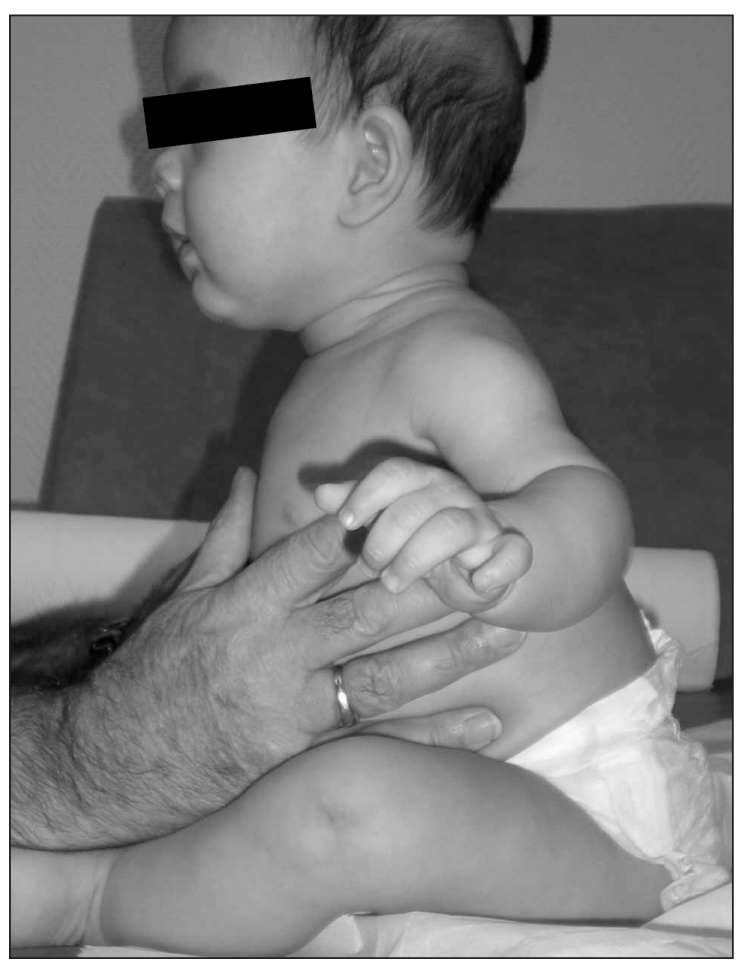

In conclusion, the diagnosis of isolated fetal hyperlordosis can be made by prenatal sonography, showing a lumbar spine in extreme hyperextension. In such cases, structural abnormalities of the spine and remaining central nervous system as well as arthrogryposis should be excluded. Complementary MRI may confirm the diagnosis; in our case, MRI did not reveal additional information, but in the third trimester, a complete detailed depiction of the fetal spine may be difficult to obtain by sonography alone.

In the absence of associated anomalies, as in our case, this rare positional anomaly of severe hyperlordosis seems to have a favorable prognosis. This information may help others in counseling patients with the same condition.

\section{References}

1. Ezaki M, Herring J. Congenital hyperextension of the lumbar spine: a case report. Calif Med 1948; 68:378-380.

2. Gardella, Bourgeois J, Bethenod M, Dumont M. Hyperextension of the fetal head associated with hyperextension of the dorso-lumbar spine: apropos of a case diagnosed in utero [in French]. J Gynecol Obstet Biol Reprod (Paris) 1983; 12:763-766.

3. MacKenzie I. Unstable lie, malpresentations, and malpositions. In: James D, Steer P, Weiner C, Gonik B (eds). HighRisk Pregnancy: Management Options. Philadelphia, PA: Saunders Elsevier; 2006:1359-1375.

4. Klein R, Haddow JE, DeLuca C. Familial congenital disorder resembling stiff-man syndrome. Am J Dis Child 1972; 124:730-731.

5. Dubois JP. Le syndrome du "Nouveau-Né raide": hypertonie musculaire congénitale familiale d'évolution régressive. Med Hyg 1983; 41:537-541.

6. Goldstein I, Makhoul IR, Weissman A, Drugan A. Hemivertebra: prenatal diagnosis, incidence and characteristics. Fetal Diagn Ther 2005; 20:121-126.

7. Shipp TD, Bromley B, Benacerraf B. The prognostic significance of hyperextension of the fetal head detected antenatally with ultrasound. Ultrasound Obstet Gynecol 2000; 15:391-396.

8. Westgren $M$, Grundsell $H$, Ingemarsson I, Mühlow A, Svennningsen NM. Hyperextension of the fetal head in breech presentation: a study with long-term follow-up. $\mathrm{Br}$ J Obstet Gynaecol 1981; 88:101-104.

9. Ballas $S$, Toaff $R$, Jaffa AJ. Deflexion of the fetal head in breech presentation: incidence, management, and outcome. Obstet Gynecol 1978; 52:653-655. 